Pre-proof: Ratio 20.3 (2007), pp.208-19.

\begin{abstract}
To desire is to want, but not necessarily to be disposed to do anything. That is to say, desiring does not necessarily involve having any disposition to act. To lend plausibility to this view I appeal to the example of whimsical desires that no action could help us to realise. What may lead us to view certain desires as whimsical is precisely the absence of any possibility of realizing them. While such desires might seem less than full-blooded, I argue that we can have full-blooded desires concerning such matters because of our (non-whimsical) concern for others. That is to say, whimsical desires can have a borrowed seriousness. The article goes on to strengthen the separability of dispositions and desires by narrowing down the concept of triggering conditions for a disposition. If we allow the triggering conditions to be too broad then it will always make sense to say that someone with a desire simply must have a disposition because, all other things being equal, they would bring about what they desire if they were able to do so.
\end{abstract}

\title{
Whimsical Desires
}

Tony Milligan

\section{I.}

In Mental Reality, Galen Strawson advances the view that it makes sense to separate out desires from dispositions to act. Action in the sense that concerns Strawson involves overt public behaviour. Treating desires as inseparable from dispositions to this sort of action (as opposed, say, to the kind of action involved in mental arithmetic) is a hallmark of what he calls 'neobehaviourism'. The latter is seen as a way of retaining a residually behaviourist (but at times unacknowledged) background assumption in the philosophy of mind. Strawson's rejection of this background assumption is a position with which I broadly sympathise. To desire is to want, but not necessarily to be disposed to do anything.

To lend plausibility to this view, we might think of a variety of desires that no action could help us to realise. A list of such desires could be fairly extensive and might include 
materially impossible desires such as wanting to fly like a bird; possible and impossible desires concerning the past (e.g. desires that something has happened and desires that the past be altered); desires we have in the absence of any belief about how to realise them; desires about the distant future; desires concerning what happens at far away places such as other planets; desires to know what it is like to be a bat; the desire for the sun to shine; and (perhaps more tenuously) desires about the basic makeup of the universe. Like Kepler or the Pythagoreans we might have strong preferences concerning the latter, but unlike them we may have no inclination to supply a demonstration or to devise some verification procedure. We might simply want matters to be thus and so.

If we allow that the items on this list qualify as desires at all, that they are sufficiently full-blooded to do so, then they will be good candidates for desires that could be held in the absence of any dispositions to act. We will not be disposed to act partly because we wouldn't know how or why any particular action could make a difference. However, it might be denied that they do qualify as desires for the very reason that they make it onto the list. In the absence of any possibility of action to realise a desire, it might seem odd to say that we had a desire at all as opposed to some form of pseudo-desire. (Anything that is not the genuine article; anything that might be mistaken for a desire.) I will accept that it is perfectly intelligible that someone might believe that they have a desire while not in fact doing so, i.e. that what seems like a desire to them might in fact not be so. In such a case, their wrongness need not be a matter of being mistaken about their inner state (in the same way that we are sometimes mistaken about our emotions) it might also involve the unintelligibility of the claimed desire. We might think here of mystics who no doubt desire many things but are all too aware that some of their claimed desires may fall off the edge of intelligibility. 
Given the concession that there is good sense in separating out real desires from pseudo-desires, it might well be charged that the desires I have listed above are instances of the latter. When someone wants something to occur on a distant planet long after our world has gone or if I say 'I hope that the basic constitution of the universe is thus and so', this might amount to no more than whimsical speculation. When someone says 'wouldn't it be fun if...' this sounds like a desire claim but we hesitate to attribute any actual desire to them. The stranger or more whimsical the speculation, the less embedded it happens to be in the regular economy of our concerns, the more plausible it will be to mark it down as an idle conjecture of some sort.

This is not to suggest that the whimsicality of wanting the sun to shine at a remote future date could be a matter only of their being no action relevant to bringing about this state of affairs. At most, this could only be a necessary but not sufficient condition of their whimsicality (and perhaps not even that). After all, there are some deep desires that leave us utterly helpless. Bereavement involves wanting and feeling that we need the person back but seeing that nothing can be done about it, and it would be wrong to view the desires of the bereaved as whimsical. Here, it might help to distinguish between helpless desires (which we cannot do anything to bring about) and whimsical desires. Not all of the former are instances of the latter although wanting the sun to shine at some distant date is an instance of both.

The unavailability of any relevant action in the case of wanting the sun to shine at a remote future date is perhaps more symptomatic than constitutive of its whimsicality. (Symptoms flag up several possibilities, in this case whimsicality is one of them.) I will take it that what is constitutive of the whimsicality of this particular helpless desire is a combination of (i) the agent viewing the matter in question as a one of no intrinsic value; and (ii) the matter 
in question lacking any embeddedness in the agent's conception of what is instrumentally required for a life to go well. ${ }^{\mathrm{i}}$ Whenever a helpless desire meets these conditions it may plausibly be regarded as whimsical.

I will accept that within the broader class of helpless desires those desires which are whimsical are also good candidates for being pseudo-desires, i.e. something other and less than the genuine article. However, if they are genuine, full-blooded desires then they will be good candidates for desires that we may have in the absence of any associated dispositions to act. By contrast, helpless desires of a sort that are deep, such as those involved in bereavement, are poor candidates. They are (perhaps invariably) associated with dispositions to act in ways that are not geared to help realise our desires. ${ }^{\text {ii }}$ The same is not obviously true for whimsical desires. To defend their full-bloodedness is consequently one way to strengthen the case for the existence of desires without dispositions.

\section{II.}

I want to maintain that there is a non-diminished, full-blooded sense in which anything at all that is intelligible is also a potential object of desire, no matter how whimsical it may seem even to the desiring agent in question. If we think of desires as involving propositional attitudes (wanting that something be the case) then the truth of any proposition can be desired. That is to say, if you can make sense of it then you can also desire it. The same point may be made in a more formal manner via the following desirability condition:

Desirability condition: For any state of affairs $S$, if $S$ is intelligible (whether its truth or falsity is verification-transcendent or otherwise) then it is possible to 
desire that $S$ be the case in a non-diminished sense.

If someone wants to say that there are desires for unintelligible states of affairs then my response is all well and good. The above conditional does not rule them out. To do that, it would have to operate in both directions and this would involve a stronger claim than the one I am seeking to defend. I am concerned only to say that whatever else may qualify as desirable, anything that satisfies the antecedent will qualify. A stronger, and perhaps tempting, version of the conditional might require that $\mathrm{S}$ is not only intelligible, but is also believable i.e. that there are no psychological constraints that make belief in $\mathrm{S}$ utterly incredible. However, to add this further requirement is not obviously necessary. It would qualify but not significantly alter my argument.

In defence of the conditional as it is given, I offer the following scenario. $\mathrm{Mr} \mathrm{Y}$ is in a room with $\mathrm{Mr} \mathrm{X}$. They are the best of friends. $\mathrm{X}$ is at a desk and has just written a paper on some more or less obscure problem. How obscure it is does not matter, just so long as what he has written is both intelligible and believable, i.e. there are no epistemic or other constraints disbarring Y's belief in the solution that X has proposed. The solution may or may not happen to be understood by $\mathrm{Y}$ or believed by him but that is a different matter. Y looks over at his friend and companion and he hopes that the latter's hard work, striving and years of application have finally paid off. He hopes, wants, desires and may do so as strongly as you like that the paper constitutes real insight and also that it is well received. He may have this desire even before he reads the paper in question and his having a desire of this sort might be an indication of friendship of the best sort. (This will turn out to be important in what follows.) Given this specification of the situation, we can say the following: what $\mathrm{Y}$ wants is not just fame and 
reputation for his friend, he also wants the paper's success to be deserved in the sense of not just merited by its cleverness but by the rightness of X's solution to the problem in question.

Suppose that $\mathrm{X}$ has presented the utterly pathbreaking theory that Torter, the weird stuff detected on a distant planet, is nothing other than $\mathrm{H}_{2} \mathrm{O}$. In such a case, if $\mathrm{Y}$ were to accurately reel off a complete list of his desires, this list would include the following: 'I want MrX to be right' although as yet we cannot tell whether $\mathrm{Y}$ would have any idea about what this rightness would involve or how plausible $\mathrm{X}$ 's theory happens to be. His desire that $\mathrm{X}$ is right might be looked upon as an unmotivated desire in the sense that its realisation would serve no ulterior purpose. It would not help to realise some further desire that is held by Y. What we want for our friends may be unmotivated in just this way. If someone were to object that the desire that $\mathrm{X}$ is right will be motivated by Y's desire that X's life go as well as possible then I will be happy to concede the point. Whether we classify Y's listed desire as a motivated or unmotivated desire will depend upon how we make sense of friendship of the best sort. (The sort I have specified to hold between $\mathrm{X}$ and $\mathrm{Y}$.)

Whatever decision we make about this, the following will hold. If Y gains access to and understands what $\mathrm{X}$ has written and reflects upon what would make it true, then the desire he lists as 'I want Mr X to be Right' can only be held by him in the fullest sense if it gives rise to a further, and this time motivated desire. He may truthfully list this second, and motivated desire as follows 'I want it to be the case that Torter $=\mathrm{H}_{2} \mathrm{O}^{\prime}$. If Y really wants his friend $\mathrm{X}$ to be right, and understands what this involves, then $\mathrm{Y}$ will desire that the world be thus and so for his friend's sake. (Allowance is made here for referential opacity: just what it is that Y desires in a motivated manner will depend upon his beliefs about what his friend is claiming.)

Y's concern about the world being thus and so can be entirely dependent upon and 
motivated by his concern about his friend and need not be the kind of thing that interests him personally. Although this argument is set out via a certain kind of puzzle, caring about another person in just this way is something that is perfectly familiar. So too is the related pleasure of reading a paper by a friend which turns out to say something surprisingly original. It is entirely intelligible that $\mathrm{Y}$ may sincerely, truthfully say 'Well, I hope you are right' and this is something that any one of us might also sincerely, truthfully say to those we care for deeply and who happen to be in the paper-writing business. Here, we might want to say that a desire for something that strikes us as utterly trivial when considered on its own, may have a borrowed seriousness when considered in the context of caring for another whose well being we view as important.

That such a desire may be held for ulterior reasons does not make it any less of a full-blooded desire. Motivated desires are desires in an entirely legitimate sense. (The gulf between having a motivated desire for something and having an unmotivated desire for it may even be one that can be bridged, although my argument does not depend upon this being so. $)^{\text {iii }}$ Moreover, the only circumstances under which Y cannot have such a motivated desire will be those under which he simply has no understanding of what $\mathrm{X}$ has written and what its truth would involve. (Perhaps the symbolism might defeat him or it might be written in an unfamiliar language.) In such a case he will still want whatever his friend has written to be true but he won't desire that anything else is the case in order to make it true.

III.

The desirability condition can now be applied to the candidate desires initially listed. These candidate desires are all of a sort that we might well be helpless to realise, such as the 
desire that the fundamental constitution of the universe be thus and so, or wanting the sun to shine at a remote future date. If there is a propositional attitude involved in each case, and this propositional attitude is both intelligible and believable, then the desirability condition will be met and the list member is a real, full-blooded desire. Take the case of desiring that something happen on a distant planet. I am inclined to think that we could have such a desire in an unmotivated manner. But even if it seemed too whimsical, we could still have such a desire in a motivated manner, out of our concern for someone else who claims that this is how things are. We might even do so while wishing that they had chosen some other (more serious) profession or topic of inquiry. Indeed, their rightness may serve as some small consolation for their unfortunate choice of research project.

Once we allow that the desires initially listed may be held by someone, and held as real desires, even though they are held in the absence of any plausible means to realise them, we might allow that someone with one of the desires in question might, out of frustration or by default, still have a disposition of sorts. They might (or must) be disposed to do various things that are not relevant to realising the desire. However, it is plausible to think that they could lack even such marginal dispositions and still have the desire in question. They might, for example, have a particularly high frustration threshold, or be resigned to acceptance. More fundamentally, given that the desire may be motivated by concern for an other, any appeal to a disposition to act out of frustration will be implausible because there may be no such frustration. If I desire that a friend's theory about what is happening in remote places is correct then I may happen to desire it while having no intrinsic or ulterior interest in this matter, and hence no plausible reason to experience and act out of frustration. (No gazing listfully at the night skies and so on.) The motivated character of such desires will undermine any appeal to 
residual dispositions to act out of frustration. Desires of the sort specified will therefore remain good candidates for desires that may be held without any dispositions to act at all.

IV.

The plausibility of this later claim will depend upon the specification of suitable constraints upon the concept of disposition and upon some account of the triggering conditions for a disposition. If we allow the triggering conditions to be too broad then it will always make sense to say that someone simply must have a disposition whenever they have a desire. It will always make sense to do so because there will always be some set of conditions, perhaps outlandish, which can be specified and which could make the desire in question realisable. For example, without the right constraints, it will always make sense to say that I presently have the disposition to create universes whenever I am transformed into a deity whose powers are directed towards just this activity. I will take it that something is going badly wrong whenever an account of dispositions legitimates claims of this sort.

To rule out such a possibility, what I want to do is to set up a constraint upon the legitimate specification of triggering conditions. To begin with, I will take it that the following is a plausible provisional account of what is involved ascribing a disposition to an agent::

D1: An agent $R$ can be said to be disposed to act, in a sense that involves engaging in overt/public behaviour, whenever $R$ is presently constituted in such a way that (all other things being equal) he will try to act in a certain way whenever a set of appropriate conditions are met. 
I will call these appropriate conditions the triggering conditions, $\mathrm{K}$, and the overt, public act that $\mathrm{R}$ is disposed to perform $\varphi$. For simplicity, I will take it that if someone is disposed to try then they are disposed to act. A paralysed person may not plausibly be said to be lacking in dispositions merely by virtue of their paralysis. They remain an agent, albeit an incapacitated one. Part of what is frustrating about their situation is precisely their having dispositions that do not lead to actions. I will also take it that the bracketed ceteris paribus clause (hereafter c.p.) allows us to set aside consideration of the 'finkish' problems that arise in those cases where we ascribe a disposition to an agent but something else always pops up to counteract or remove the disposition. The desirability of the move is just this: finkish problems leave a question mark over whether an agent really does have the disposition in question. ${ }^{\text {iv }}$

With these qualifications in mind, we may proceed. Suppose that $\mathrm{R}$, as an ordinary rational person, has a desire that $\mathrm{x}$ and this is a desire concerning some past circumstance i.e. it is the kind of desire that leaves $\mathrm{R}$ feeling helpless and unable to affect matters. What is also assumed here is both that desires concerning the past are full-blooded desires and that $\mathrm{R}$ does not have the kind of belief that would lead him to hold that the past might be alterable. ${ }^{\mathrm{v}}$ While $\mathrm{R}$ wants, hopes, wishes that $\mathrm{x}$, he also has no belief that any action that he could undertake would be relevant to bringing it about. He does not believe that x can be brought about directly, by time travel or by altering the truth conditions of statements concerning the past. He also does not believe that the past can be altered indirectly by beseeching either God or some other well-placed agent. Under these circumstances, it looks as if R may have a desire of the sort that Strawson tries to make room for, i.e. a desire that is quite separable from any disposition to act. If this is so, then the case of $\mathrm{R}$ points towards the separability of dispositions and desires.

However, a problem emerges once we introduce the epistemic constraints given above 
and restrict what $\mathrm{R}$ is allowed to believe. Once such constraints are introduced, a counterfactual claim may be made such that if only $\mathrm{R}$ believed that he had a way to affect matters then (c.p.) we would already have a specification of the conditions $\mathrm{K}$ under which he would be disposed to act in the relevant manner. And if we say this, then are we not effectively saying that he already has a disposition to act under the right conditions just so long as the latter are specified in plausibly broad terms? And these right conditions need not be at all outlandish. All we have done is to expand our account of the triggering conditions by committing to an assumption of the following sort:

D2: An agent $R$ can be said to be disposed to $\varphi$ whenever certain triggering conditions $K$ are met, and these conditions include R's belief that $\varphi$-ing may help to bring about $x$ (c.p.)

Here, I will follow Strawson and say that the notion of a set of triggering conditions may be stretched too far and that this is precisely what the above claim does even though it specifies nothing of an outlandish sort. However, while I will endorse the constraint that Strawson identifies, I also want to suggest that a further constraint is necessary to rule out certain non-outlandish transformations. Strawson's constraint is as follows:

C1: The conditions $K$ under which the dispositions of anything are triggered cannot include the transformation of that thing into an agent.

If we fail to impose this constraint then we will be committed to attributing all manner of 
dispositions (to laugh, dance, cry and perform particularly difficult feats of mathematics) to inanimate objects, dispositions that are normally and plausibly reserved for persons. ${ }^{\text {vi }}$ Suppose that I have a disposition to applaud at the end of Tristran and Isolde. While others might lament and decry my formidable powers of musical endurance, it does not mean that a pile of chemicals equivalent to those which make up my body also has a disposition to applaud under the same conditions plus an extra triggering condition (the condition of being organised in a me-like manner). I will take it that Strawson is right about this constraint. Dispositions are activated by changes but not by changes that bring about agency.

But what $\mathrm{C} 1$ rules out is only the inclusion of a certain kind of outlandish condition within the set of triggering conditions $K$. What it does not rule out is any changes in an existing agent. It certainly does not mean that the changes resulting in an action can only involve changes in the world (although, on a rough and ready account of dispositions this is how we might tend to think of matters). Such a constraint, ruling out any change in the agent, would be excessive. Returning to the case of $\mathrm{R}$, we can see what would make it excessive: (i) before R's disposition is triggered he will have to see/construe/come to believe that the situation is of a particular sort, and this amounts to a change in the agent and not just in the world. Similarly, I am disposed to applaud at the end of the aforementioned musical extravaganza when I see that or believe that it is the end. If I get this wrong, if, for example, I nod off and loose my place, then I will not be disposed to applaud merely because the external conditions are right; (ii) there are lots of disposition triggers that are a matter of how we feel and what we experience quite apart from anything that is going on beyond the bounds of the self. Whenever I have a pain in my foot, I may be disposed to shake my leg; whenever I believe (mistakenly or otherwise) that I am in danger I run away screaming and waving my arms vigorously; 
whenever I think of him I want to cry, and so on.

While some changes in the agent, changes that are less radical that agency-inducing change, may be viewed as legitimate disposition triggers others should be ruled out. Suppose I were to claim that Ghandi had a disposition towards mass murder but it was just a wee bit different from that of Jack the Ripper's disposition towards a similar series of actions. In support of this I might say the following. If Ghandi had come to believe that it was desirable to engage in serial murder under the right conditions and also to believe that these conditions were met, then he would have tried to act accordingly (c.p). But this is plainly absurd and not just because of a determination to preserve the reputation of the individual in question. Nor is it just a matter of concern about counterfactuals in general. It is absurd because of the way it collapses the distinction between standing dispositions, of a sort all humans have, and those that vary from person to person. (Such as the aforementioned murderous disposition.) That is to say, such an approach wouldn't allow the concept of a disposition to do all the work that we require it to do.

To avoid this problem I will formulate an appropriate constraint upon triggering conditions to rule out some kinds of agent change:

C2: The triggering conditions $K$ given which an agent $R$ can be said to be disposed to perform some particular action cannot include changes in (i) beliefs concerning what is a desirable outcome; and/or (ii) beliefs concerning which acts are relevant to bringing a particular desired outcome about.

If we do not introduce the constraint on changes of type (i), or at least some similar constraint, 
then attributions of dispositions will cease to be useful for tracking significant differences of character. To say that someone would $\varphi$ if only they believed that it was right and proper to do so, and that the opportunity to $\varphi$ really can arise, is not to attribute any disposition to them at all as they are now. Instead, it tells us about what would have to happen to them, what alterations to the person would have to take place, before they came to have the disposition in question.

Similar considerations apply in the case of type (ii) changes. To say that $\mathrm{R}$ would be disposed to $\varphi$ if only he believed that it would make a difference, tells us about one kind of alteration that would lead to $\mathrm{R}$ having the disposition in question. It does not specify the right conditions under which he is already disposed to act. But suppose we were to allow that $\mathrm{R}$ just happens to be disposed to form such a belief and to do so in the nick of time, whenever the other relevant conditions arise. Here, we might say something like this: a triggering condition for disposition is the triggering for disposition $_{1}$ i.e. he is already disposed to see that $\varphi$-ing would work and to see this just in the nick of time. For example, we might say that if $\mathrm{R}$ has practical wisdom then he would $\varphi$ whenever circumstances were thus-and-so because whatever his current beliefs, he would see what to do when the situation arose. Could we not plausibly say that, by virtue of this, R already has a disposition not just to see the efficacy of $\varphi$-ing but already has a disposition to $\varphi$ ? Against this, I suggest that we turn back to Strawson and concede that in such circumstances, $\mathrm{R}$ would only have a disposition to form a disposition to $\varphi$ and nothing more. vii $^{\text {ii }}$

Perhaps one might consider, as some commentators on Strawson have, that such a distinction between first and second-order dispositions is a mere quibble. (Or at least a quibble in this particular context.) $)^{\text {viii }}$ However, I want to conclude by pointing out the real work that 
such a distinction does within approaches towards ethics that place emphasis upon variable character. (Virtue ethics would be one example.) If we have disreputable first-order dispositions then like the notorious Jack we are morally blameworthy and/or corrupt. If we have disreputable second-order dispositions then we are, at worst, morally weak, and such weakness may vary from person to person or it may be a shared human flaw. Within a character-centred ethical framework, the distinction between first and second-order dispositions is more than a quibble. Anyone who places considerable emphasis upon variable character, as opposed e.g. to a character sceptic, will have good reason to adopt a version of the constraint upon triggering conditions set out in $\mathrm{C} 2$. Once this move is made, and the defensible attribution of dispositions is suitably restricted, the case for whimsical desires as desires that may be held without any accompanying dispositions is strengthened.

\section{References}

Harman, G. (1976). 'Practical Reason,' The Review of Metaphysics, 29 No. pp.431-63.

Hursthouse, R. (1991). 'Arational Actions,' Journal of Philosophy, 88 No.2. pp. 57-68.

Martin, C.B. (1994). 'Dispositions and Conditionals,' The Philosophical Quarterly, No.44, pp.1-8.

Parfit, D. (1984). Reasons and Persons, Oxford: OUP.

Pugmire, D. (2005). Sound Sentiments: Integrity in the Emotions, Oxford: OUP.

Ridley, A. (1995). Music, Value and the Passions, Ithica, NY: Cornell University Press.

Smith, M. (1998), 'Galen Strawson and the Weather Watchers,' Philosophy and 
Phenomenological Research, 58 No.2 pp.449-54.

Strawson, G. (1994). Mental Reality, Cambridge MA: MIT.

\footnotetext{
${ }^{\mathrm{i}}$ This idea of embeddedness as partly constitutive of the depth of a response owes something to Quine's treatment of necessary truths as a matter of the sheer volume of other propositions which depend upon them. The theme is reworked as a criterion of depth by Ridley (1995), 154-6 and by Pugmire (2005), 39-45.

ii Hursthouse (1991) calls such futile actions by the grief-stricken 'arational'.

iii Harman (1976). Although I would want to qualify this by allowing that a desire for evil is perhaps only conceivable as a motivated desire. Milton's Satan is out for power and revenge, he is not evil for evil's sake.

iv Martin (1994).

$v$ For the full-bloodness of desires concerning the past see Parfit, (1984), 170-171.

vi Strawson (1994), 272-3.

vii Strawson (1994), 273, 276-7.

viii Smith (1998), 453.
} 